\title{
Dependence of the Generation Behavior of Charged Nanoparticles and Ag Film Growth on Sputtering Power during DC Magnetron Sputtering
}

\author{
Gil Su Jang ${ }^{1} \cdot$ Du Yun Kim ${ }^{1}$. Nong-Moon Hwang ${ }^{1}$ (D)
}

Received: 19 October 2020 / Accepted: 3 December 2020 / Published online: 13 January 2021

(c) The Author(s) 2021

\begin{abstract}
Effects of sputtering power on the deposition rate and microstructure, crystallinity, and electrical properties of $\mathrm{Ag}$ films during direct current (DC) magnetron sputtering are investigated. Thin films $(\sim 100 \mathrm{~nm})$ are deposited at sputtering powers of 10, 20, 50, 100,200 and $300 \mathrm{~W}$ and analyzed by field-emission scanning electron microscopy (FESEM), X-ray diffraction (XRD), transmission electron microscopy (TEM) and a four-point probe. The film deposited at a sputtering power of $10 \mathrm{~W}$ has the lowest growth rate, but the highest crystalline quality, with the lowest full width at half maximum (FWHM) and the lowest resistivity. The film deposited at a sputtering power of $200 \mathrm{~W}$ has the highest growth rate, and the second best crystalline quality in view of FWHM and resistivity. The film deposited at a sputtering power of $50 \mathrm{~W}$ has the moderate growth rate, and the worst crystalline quality in view of FWHM and resistivity. High-resolution TEM observations reveal that films deposited at sputtering powers of 10 and $200 \mathrm{~W}$ have far fewer defects, such as grain boundaries, dislocations and stacking faults than those deposited at a sputtering power of $50 \mathrm{~W}$. Such deposition behavior could be explained by sputtering power, which affected the generation of the charged nanoparticles. And the high quality of films could be obtained at a high deposition rate, in which charge plays an important role.
\end{abstract}

\section{Graphic Abstract}
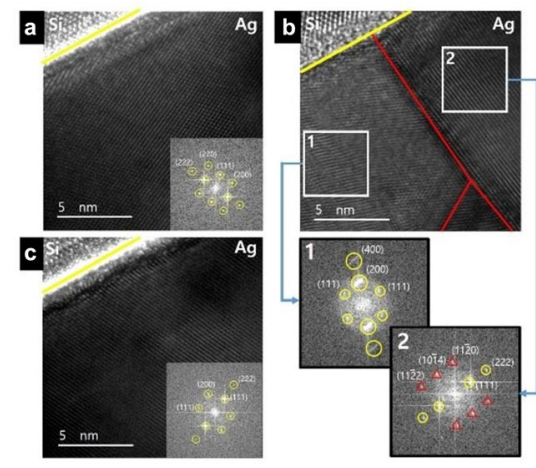

HRTEM and FFT images of Ag films deposited on Si substrates at sputtering power of (a) $10 \mathrm{~W}$ (b) $50 \mathrm{~W}$ and (c) $200 \mathrm{~W}$

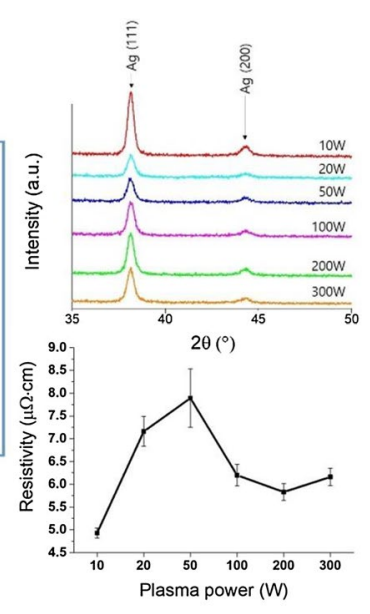

Keywords Sputtering power $\cdot$ DC magnetron sputtering $\cdot$ Ag $\cdot$ Thin films $\cdot$ Bias $\cdot$ Charged nanoparticles

Nong-Moon Hwang

nmhwang@snu.ac.kr

1 Department of Materials Science and Engineering, Seoul

National University, 1 Gwanak-ro, Gwanak-gu, Seoul,

Republic of Korea 


\section{Introduction}

In general, crystal growth can be described using a terraceledge-kink (TLK) model [1], where the building block is an atom, ion or molecule. However, several phenomena are difficult to explain using the TLK model but can be explained by the so-called non-classical crystallization mechanism, where the building block is nanoparticles [2-16].

Hwang et al. [7] reported that, for thin film growth by chemical vapor deposition (CVD), most films and nanostructures are grown by charged nanoparticles (CNPs) as building blocks. It was reported that the charge plays a very important role in the evolution of dense films and nanostructures: neutral nanoparticles produce a porous structure, whereas CNPs produce a dense structure. For example, Yoon et al. [17] compared the deposition behavior of charged silicon nanoparticles between electrically floating and grounded silicon substrates, and observed that silicon nanowires or dense films were grown on the floating substrate, whereas a porous structure was grown on the grounded substrate.

Park et al. [18] compared the plasma dewetting kinetics of Sn films, deposited by sputtering on a native oxide of silicon, between floating and grounded conditions of the surface, and observed that the plasma dewetting kinetics were much faster in the floating condition than in the grounded one. Based on such deposition behavior of CNPs, they suggested that charge enhances the atomic mobility of nanoparticles or renders them liquid-like. By exploiting the liquid-like property of CNPs, Park et al. [19] deposited a fully epitaxial silicon film on a silicon wafer at $550{ }^{\circ} \mathrm{C}$ under a substrate bias of $-1000 \mathrm{~V}$ using radio frequency plasma-enhanced chemical vapor deposition (RF-PECVD).

Although film growth by CNPs has been studied extensively in CVD, there have been fewer reports on film growth by CNPs using physical vapor deposition (PVD) methods, such as sputtering. Yoshida et al. [20, 21] reported the concept of film growth by 'hot cluster epitaxy' or 'plasma flash evaporation', where nanoparticles were evaporated by thermal plasma and the condensed clusters contributed to film growth. Although they did not mention the role of charge, we believe that their clusters were charged. Kwon et al. [22] confirmed the generation of Ti CNPs, and their contribution to film deposition during RF magnetron sputtering. Jang et al. [23] also confirmed the generation of negatively charged Ag nanoparticles, and their contribution to film deposition during DC magnetron sputtering.

This study is an extension of this previous work [23], focusing on the effect of sputtering power on the deposition behavior of films during DC magnetron sputtering. The key finding of this study is that most of the sputtered flux is in the form of individual atoms under a low sputtering power of $10 \mathrm{~W}$, while neutral clusters are generated when the sputtering power is
20-50 W, and charged clusters when the sputtering power is 100-300 W.

\section{Experiment}

Ag thin films were deposited on a p-type Si (100) substrate by DC magnetron sputtering. The silicon substrate was blown with air to remove dust. After that, it was immersed in an ethanol solution and ultra-sonication was conducted for 10 min to remove contaminants. The DC magnetron sputtering chamber was the same as used in [23]. An Ag target $7.62 \mathrm{~cm}$ in diameter (99.999\% purity) was used. The Ag target was connected to a DC power supply (psplasma, Inc., SDC1022A, Hwaseong, South Korea), and the distance between the target and substrate was fixed at $24 \mathrm{~cm}$. The substrate was placed in an electrically floating holder to apply the electrical bias. A grounded $\mathrm{Cu}$ mesh was installed on the substrate holder so that the bias would not affect the plasma. The hole size of the grounded mesh was shorter than the Debye length of the plasma, to prevent the plasma from affecting the substrate, and the area of each square hole was $150 \mu \mathrm{m} \times 150 \mu \mathrm{m}$. The deposition of $\mathrm{Ag}$ films was started by opening, and terminated by closing, the shutter, which was installed above the grounded mesh.

The base pressure of the chamber was $\sim 3 \times 10^{-6}$ mTorr, and the working pressure was maintained at $10 \mathrm{~m}$ Torr using Ar gas. The substrate at room temperature was slightly heated during sputtering. However, the temperature, measured by a thermocouple placed near the substrate, did not exceed $120{ }^{\circ} \mathrm{C}$ even at the highest sputtering power of $300 \mathrm{~W}$. To study the effect of sputtering power on the deposition behavior of Ag films, DC sputtering powers of 10, 20, 50, 100, 200 and $300 \mathrm{~W}$ were applied. Since the thin film deposited at the sputtering power of $10 \mathrm{~W}$ has a very low deposition rate, it was difficult to analyze the resistivity by a four-point probe and the crystallinity by XRD if the deposition time is the same as that of the other sputtering power. Because of this problem, we tried to fix the film thickness to $100 \mathrm{~nm}$. To achieve this, Table 1 shows deposition times for each sputtering power.

In addition, to determine whether charged particles contribute to film deposition during sputtering, biases of $-300,0$ and $+300 \mathrm{~V}$ were applied to the substrate holder at plasma powers of 10 and $200 \mathrm{~W}$. Deposition times of 420 and 20 min were used for the plasma powers of 10 and $200 \mathrm{~W}$, respectively, to produce films of similar thickness.

The surface and cross-section of the Ag films were observed by field-emission scanning electron microscopy (FESEM; SUPRA; Carl Zeiss, Oberkochen, Germany) at an accelerating voltage of $2 \mathrm{kV}$. A focused ion beam (FIB; SMI3050SE; Seiko Instruments, Chiba, Japan) was used to prepare the sample for observation by transmission electron 
microscopy (TEM; Tecnai F20; FEI, Hillsboro, OR, USA) at an accelerating voltage of $200 \mathrm{kV}$. To examine the crystallinity, the deposited Ag films were analyzed by XRD (PANalytical, X'Pert-Pro, Almelo, The Netherlands) at a $2 \theta$ scanning range of $30^{\circ}-80^{\circ}$ with a $\mathrm{Cu} \mathrm{K \alpha}(\lambda=1.5418 \AA$ ) source. To evaluate the electrical property of the film, the resistivity was measured using a four-point probe (CMT-SR2000N; Materials Development Corporation, Founex, Switzerland).

\section{Result and Discussion}

Figure 1 shows cross-sectional FESEM images of the Ag films deposited on the Si substrates at different sputtering powers. Depending on the sputtering power, it took 25-700 min to deposit Ag films of $\sim 100 \mathrm{~nm}$. The average value of the film thickness was obtained by measuring 10 locations of the cross section using FESEM. The average value was presented with an error range of $95 \%$ confidence. The film growth rate was determined by dividing the measured film thickness by the deposition time. The dependence of the film growth rate on the sputtering power is shown in Table 2.

The film growth rate increased with increasing sputtering power up to $200 \mathrm{~W}$, although not linearly, and then decreased at $300 \mathrm{~W}$. The reason for the decreasing film growth rate at a sputtering power of $300 \mathrm{~W}$ is re-sputtering caused by the high-energy sputtered flux [24].

Figure 2 shows top-view FESEM images of the surface morphology of the Ag films deposited on Si substrates for different sputtering powers. The grain size for each sputtering power is shown in Table 3.

The grain size was largest at the sputtering power of $10 \mathrm{~W}$, and tended to decrease with increasing sputtering power. In general, the grain size of thin films is known to be proportional to the crystallinity [25]. Since the grain size decreased with increasing sputtering power, the crystallinity of the films was expected to decrease with increasing sputtering power. To confirm this, the crystallinity of the Ag films was analyzed by XRD.

Figure 3 shows the XRD data of Ag films deposited at sputtering powers of $10,20,50100,200$ and $300 \mathrm{~W}$ in the $2 \Theta$ range of $35^{\circ}-50^{\circ}$. The peaks at $2 \theta=38.11^{\circ}$ and $44.27^{\circ}$ indicate the (111) and (200) orientations of $\mathrm{Ag}$, respectively. The crystallinity was examined based on the full width at half maximum (FWHM) intensity of the (111) peak, and using the Scherrer equation:
$\tau=\frac{K \lambda}{\beta \cos \theta}$

where $\tau$ is the mean grain size, $K$ is a dimensionless shape factor, $\lambda$ is the $\mathrm{X}$-ray wavelength of $\mathrm{Cu} \mathrm{K} \alpha_{1}, \beta$ is the FWHM and $\theta$ is the Bragg angle. Equation (1) shows that $\beta$ is inversely proportional to $\tau$. Therefore, the smaller the FWHM, the better the crystallinity [26]. Table 4 shows the FWHM values of the $\mathrm{Ag}$ films deposited at different sputtering powers.

As shown in Fig. 3 and Table 4, the Ag film deposited at the sputtering power of $10 \mathrm{~W}$ exhibits the highest (111) peak intensity and the smallest FWHM value, of 0.36 . Notably, the film deposited at $200 \mathrm{~W}$, rather than the film deposited at $20 \mathrm{~W}$, has the second best crystallinity, with an FWHM value of 0.38 , while the film deposited at $300 \mathrm{~W}$ has the third best crystallinity with a FWHM value of 0.41 . The films deposited at 20, 50 and $100 \mathrm{~W}$ have the same FWHM value, of 0.46 . However, the (111) peak intensity is highest for the film deposited at $100 \mathrm{~W}$, which has the fourth best crystallinity.

The Ag film deposited at $10 \mathrm{~W}$ was predicted to have the highest crystallinity because it had the largest grain size (see Fig. 2a). This prediction was confirmed, as this film had the lowest FWHM value (see Table 4). However, the prediction that the smallest grain sizes identified in the films deposited at 200 and 300 W in Fig. 2e and $f$ would correspond to the poorest crystallinities was not supported; the films deposited at 200 and $300 \mathrm{~W}$ had the second and third lowest FWHM values, as shown in Table 4. To determine why the grain size results were not in agreement with the FWHM values, the resistivity of the deposited films was measured using a four-point probe.

Figure 4 shows the resistivities of the Ag films, which were $4.93 \pm 0.11,7.61 \pm 0.33,7.89 \pm 0.64,6.2 \pm 0.24,5.83 \pm 0.19$ and $6.16 \pm 0.19 \mu \Omega \mathrm{cm}$ for sputtering powers of $10,20,50$ 100,200 and $300 \mathrm{~W}$, respectively. The bulk resistivity of $\mathrm{Ag}$ is $1.59 \mu \Omega \mathrm{cm}$. As expected from the FWHM value, the Ag films deposited at sputtering powers of 10 and $200 \mathrm{~W}$ had the lowest and second lowest resistivities, respectively, $(4.93 \pm 0.11$ and $5.83 \pm 0.19 \mu \Omega \mathrm{cm})$. Therefore, the FWHM value and resistivity of the film deposited at $200 \mathrm{~W}$ were unexpected, considering the grain size of the film (see Fig. 3e). The increased resistivity of $6.16 \pm 0.19 \mu \Omega \mathrm{cm}$ for the $\mathrm{Ag}$ film at the sputtering power of $300 \mathrm{~W}$ was due to the damage caused by the high-energy sputtered flux [27].

One possible explanation for this disagreement is that the grain size presumed from the surface morphology shown in Fig. 2 might be different from the actual grain size of the film, which should be evaluated by reference to grain boundary
Table 1 Deposition time for $\sim 100 \mathrm{~nm}$ film thickness for each sputtering power

\begin{tabular}{lllllll}
\hline & $10 \mathrm{~W}$ & $20 \mathrm{~W}$ & $50 \mathrm{~W}$ & $100 \mathrm{~W}$ & $200 \mathrm{~W}$ & $300 \mathrm{~W}$ \\
\hline Deposition time $(\min )$ & 700 & 210 & 90 & 50 & 25 & 28 \\
\hline
\end{tabular}



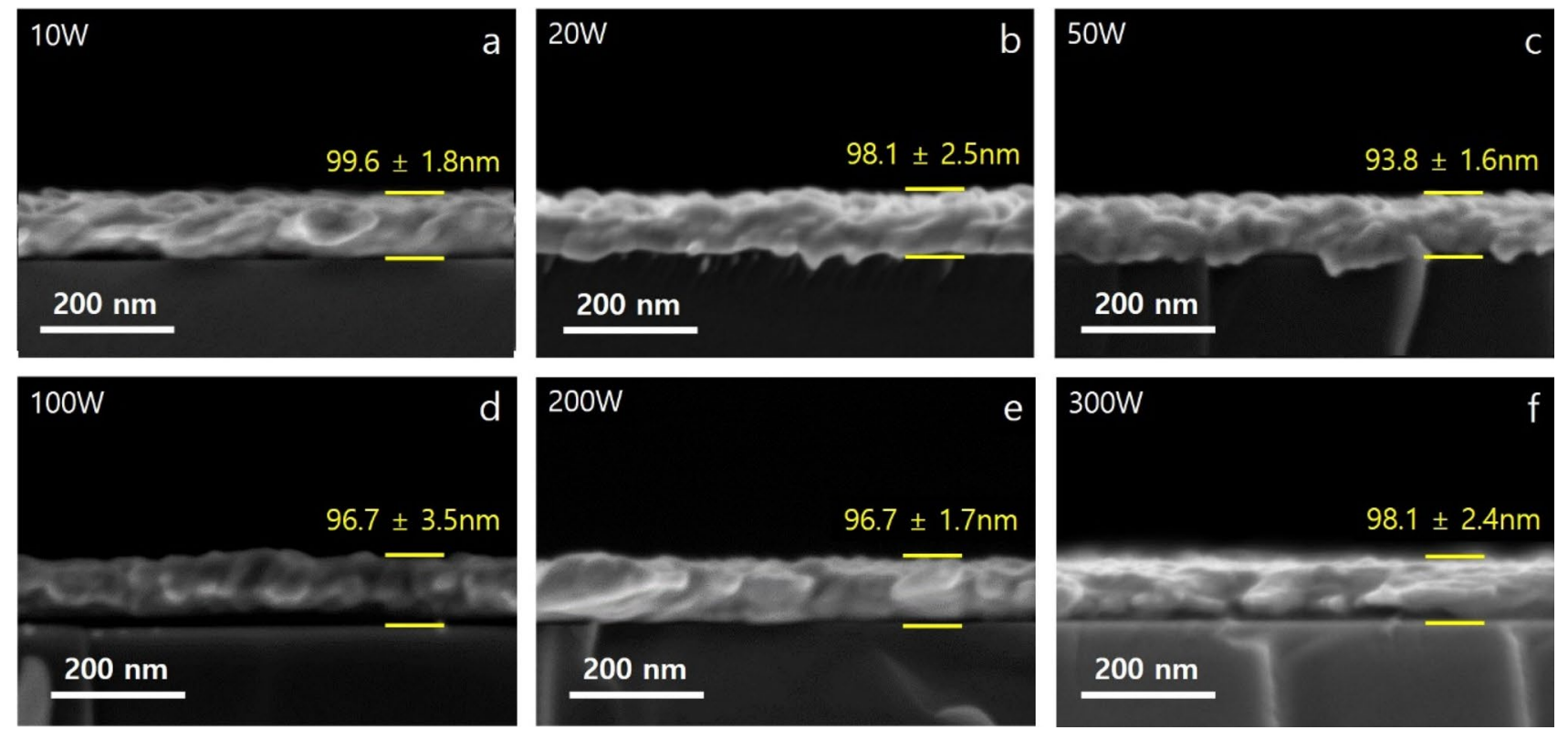

Fig. 1 Cross-sectional FESEM images of Ag films deposited on Si substrates at sputtering powers of a $10 \mathrm{~W}$ b $20 \mathrm{~W}$ c $50 \mathrm{~W}$ d $100 \mathrm{~W}$ e $200 \mathrm{~W}$ and $\mathbf{f} 300 \mathrm{~W}$

Table 2 The film growth rate for each sputtering power

\begin{tabular}{lllllll}
\hline & $10 \mathrm{~W}$ & $20 \mathrm{~W}$ & $50 \mathrm{~W}$ & $100 \mathrm{~W}$ & $200 \mathrm{~W}$ & $300 \mathrm{~W}$ \\
\hline Growth rate $(\mathrm{nm} / \mathrm{min})$ & $0.14 \pm 0.002$ & $0.44 \pm 0.01$ & $1.04 \pm 0.02$ & $1.93 \pm 0.07$ & $3.86 \pm 0.06$ & $3.50 \pm 0.08$ \\
\hline
\end{tabular}
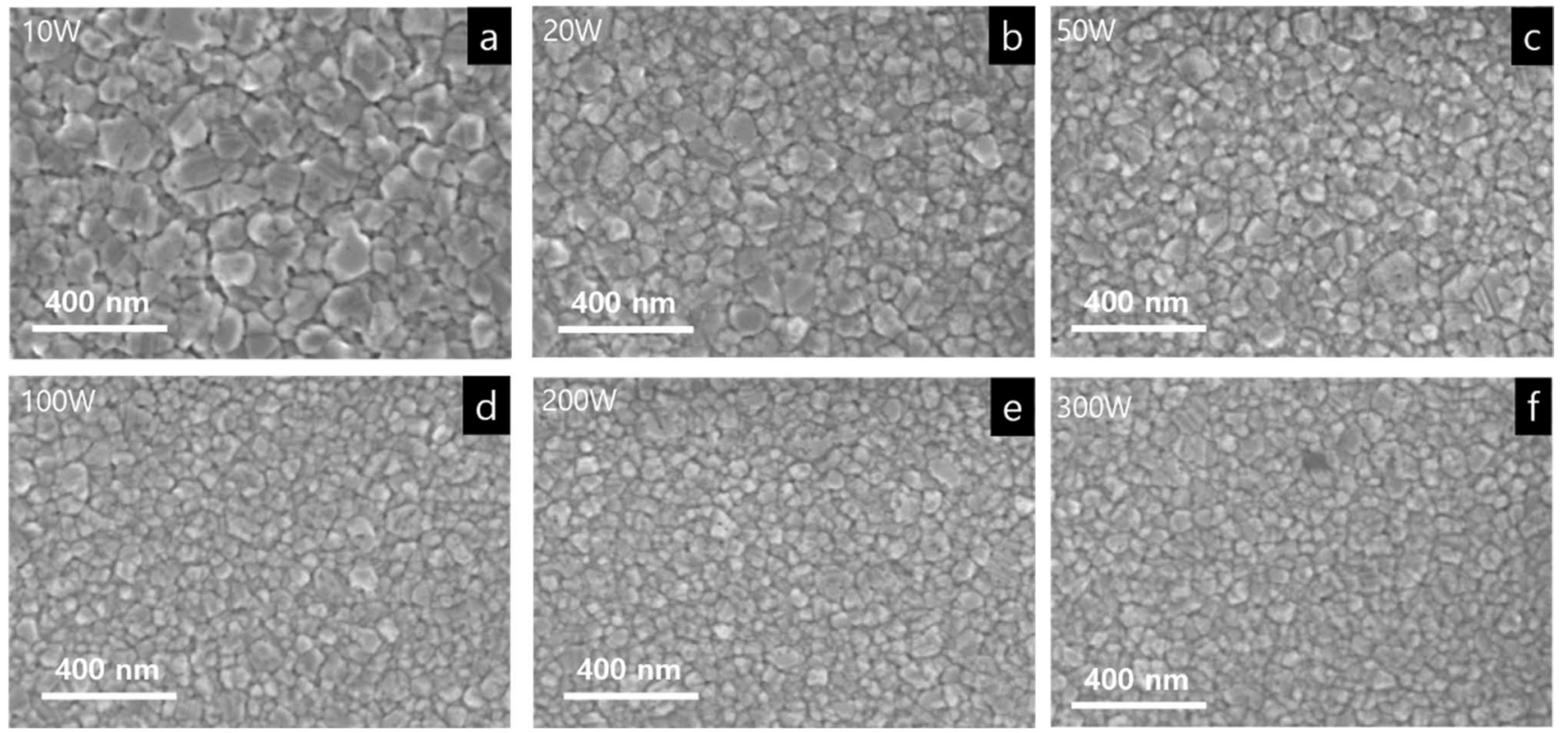

Fig. 2 Top-view FESEM images of the Ag films deposited on Si substrates at sputtering powers of a $10 \mathrm{~W}$ b $20 \mathrm{~W}$ c $50 \mathrm{~W}$ d $100 \mathrm{~W}$ e $200 \mathrm{~W}$ and $\mathbf{f} 300 \mathrm{~W}$ 
Table 3 Grain size of Ag films deposited on Si substrates for each sputtering power

\begin{tabular}{lllllll}
\hline & $10 \mathrm{~W}$ & $20 \mathrm{~W}$ & $50 \mathrm{~W}$ & $100 \mathrm{~W}$ & $200 \mathrm{~W}$ & $300 \mathrm{~W}$ \\
\hline Grain size $(\mathrm{nm})$ & $134 \pm 27$ & $87 \pm 13$ & $67 \pm 8$ & $51 \pm 6$ & $47 \pm 6$ & $50 \pm 4$ \\
\hline
\end{tabular}

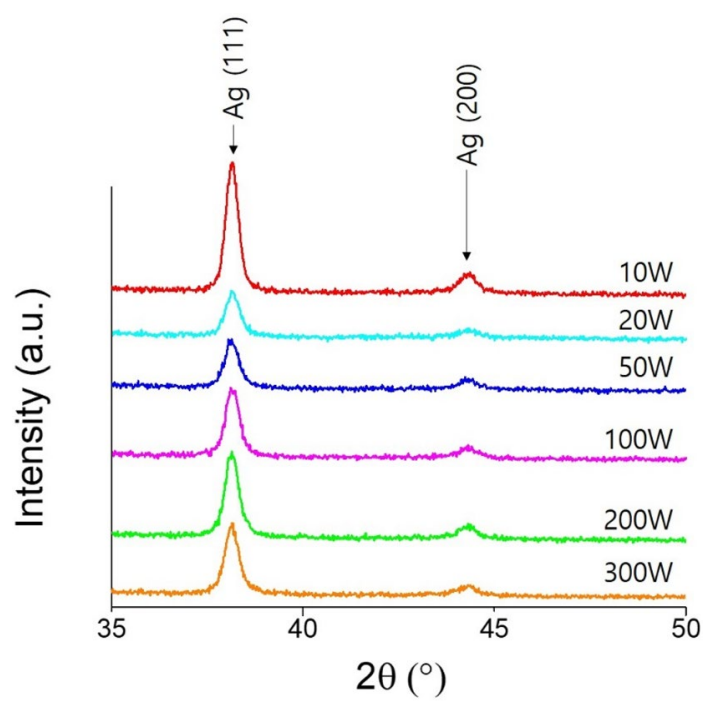

Fig. $3 \mathrm{XRD}$ data of the $\mathrm{Ag}$ films deposited at the sputtering powers of $10,20,50,100,200$ and $300 \mathrm{~W}$ in the $2 \theta$ range of $35^{\circ}-50^{\circ}$

observations. To analyze the grain boundaries and film quality, the Ag films deposited at 10,50 and $200 \mathrm{~W}$ were observed by TEM, the samples for which were prepared by FIB.

Figure 5 shows low-magnification TEM images of the Ag films deposited at sputtering powers of 10, 50 and $200 \mathrm{~W}$, respectively. Figure 5a and c show the single-crystalline region without grain boundaries, whereas Fig. 5b shows the polycrystalline region with grain boundaries, stacking faults and dislocations.

The characteristics are more clearly visible in the highresolution TEM and fast Fourier transform (FFT) images shown in Fig. 6. The (111) lattice and FFT images in Fig. 6a and $\mathrm{c}$ confirm that the $\mathrm{Ag}$ films were single-crystalline and free of defects, with a 3C-Ag face-centered cubic (FCC) structure. Although other areas of the Ag films deposited at 10 and $200 \mathrm{~W}$ had some grain boundaries and dislocations, they were very infrequent compared to the Ag film deposited at $50 \mathrm{~W}$.

The (111) lattice and FFT images in Fig. 6b confirm that the $\mathrm{Ag}$ film consisted of three grains with different orientations. The lattice image of the square area designated as ' 1 ' in Fig. $6 \mathrm{~b}$ revealed that the lattice was misaligned because of stacking faults, in turn, due to a large number of (111) dislocations. It should be noted that the (200) peaks in the FFT images in Fig. $6 \mathrm{a}$ and $\mathrm{c}$ are shown as points, whereas the (200) and (400) peaks in the FFT images in Fig. 6b are shown as lines, indicating elongation of the (200) and (400) planes caused by multiple stacking faults at various intervals. The lattice and FFT images of the square area designated as ' 2 ' in Fig. 6 b revealed that the $3 \mathrm{C}$ (FCC) and $4 \mathrm{H}$ (hexagonal close-packed (HCP)) stackings coexist, with the red triangles and yellow circles in the figure representing the HCP and FCC lattices, indicating the presence of stacking faults [28]. It should be noted that the (1014) peak in the FFT image of Fig. 6b is unique to the HCP structure [29]. Therefore, grain boundaries, dislocations and stacking faults existed in the Ag film deposited at a sputtering power of $50 \mathrm{~W}$, as shown in Fig. 6 b.

Figure 6 indicates that the density of defects such as grain boundaries, stacking faults and dislocations in the $\mathrm{Ag}$ films increases as the sputtering power increases from 10 to $50 \mathrm{~W}$, and decreases as the sputtering power increases from 50 to $200 \mathrm{~W}$. It is intuitive that the defect density increases as the sputtering power increases from 10 to $50 \mathrm{~W}$, as Ag clusters are expected to be formed during the sputtering process as the sputtering power increases. Ag clusters can be directly sputtered from the target, or formed in the gas phase via collisions among sputtered atoms. However, it is difficult to understand why the defect density decreases as the sputtering power increases from 50 to $200 \mathrm{~W}$, because it is expected that larger Ag clusters are formed in the sputtering process at $200 \mathrm{~W}$ compared to $50 \mathrm{~W}$.

One possible explanation is that larger Ag clusters can be more easily charged than smaller Ag clusters, because the ionization potential and electron affinity of large Ag clusters approach the work function of bulk Ag, whereas those of smaller Ag clusters, such as dimers and trimers, approach the ionization potential and electron affinity of a single $\mathrm{Ag}$ atom. In other words, the ionization potential and electron affinity of larger Ag clusters would be much smaller and larger, respectively, than those of smaller Ag clusters. As a result, the probability of positive or negative charging of larger Ag clusters would be much higher than that of smaller Ag clusters. According to the theory of CNPs suggested by Hwang [7], charged clusters less than $2 \mathrm{~nm}$ in size tend
Table 4 The FWHMs of (111) peaks for each sputtering power

\begin{tabular}{lllllll}
\hline & $10 \mathrm{~W}$ & $20 \mathrm{~W}$ & $50 \mathrm{~W}$ & $100 \mathrm{~W}$ & $200 \mathrm{~W}$ & $300 \mathrm{~W}$ \\
\hline FWHM $\left(^{\circ}\right)$ & 0.36 & 0.46 & 0.46 & 0.46 & 0.38 & 0.41 \\
\hline
\end{tabular}




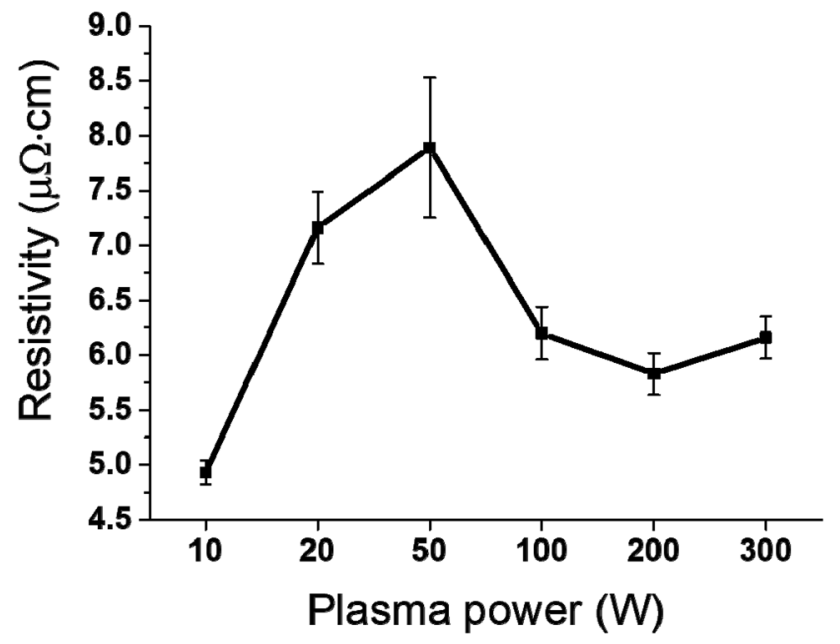

Fig. 4 Resistivity of the Ag films deposited at the sputtering powers of $10,20,50,100,200$ and $300 \mathrm{~W}$

to be liquid-like because the bond strength is weakened by charge.

From this possibility, the following scenario can be proposed. At a sputtering power of $10 \mathrm{~W}$, the sputtered flux would be relatively small and would mostly consist of single atoms, producing the Ag film with the highest quality, although at an extremely low growth rate. At a sputtering power of $50 \mathrm{~W}$, the sputtered flux would be moderate and there would be some clusters, which would lead to the generation of defects such as grain boundaries, stacking faults and dislocations; the growth rate would be moderate. At a sputtering power of $200 \mathrm{~W}$, the sputtered flux would be relatively large and more clusters would be formed, some of which would be large enough to be charged. These charged clusters would be liquid-like, producing a high-quality film. The growth rate of the film would also be relatively high. Under some conditions, the quality of a thin film deposited at a very high rate may be better than that of a thin film deposited at a low rate [30]. At a sputtering power of $300 \mathrm{~W}$, the sputtered flux would be large and more clusters would be formed than at the sputtering power of $200 \mathrm{~W}$. However, since the energy of the sputtered flux is high at this sputtering power, the growth rate of the Ag film is reduced and the damage is caused by resputtering, which deteriorates the film quality.

According to this scenario, most of the flux at a plasma power of $10 \mathrm{~W}$ would be neutral, whereas some of the flux at a plasma power of $200 \mathrm{~W}$ would be electrically charged. An intermediate fraction of the flux would be charged at a plasma power of $50 \mathrm{~W}$. If some flux is charged, the deposition behavior would be affected by the bias applied to the substrate. It is therefore necessary to measure the effect of the charge under a plasma power of $200 \mathrm{~W}$. To investigate the charge effect, thin films were deposited for 20 min while applying biases of $+300,0$ and $-300 \mathrm{~V}$ to the substrate at a plasma power of $200 \mathrm{~W}$, and the same experiment was performed at a plasma power of $10 \mathrm{~W}$ for comparison. Since the deposition rate was very slow at the plasma power of $10 \mathrm{~W}$, the film was deposited for $420 \mathrm{~min}$.

Figure 7 shows Ag films deposited with substrate biases of $-300,0$ and $+300 \mathrm{~V}$, respectively, at a sputtering power of $10 \mathrm{~W}$. The film thicknesses in Fig. 7 are $64.4 \pm 1.1$, $64.4 \pm 1.8$ and $63.0 \pm 2.7 \mathrm{~nm}$, respectively. The thickness of the Ag films was not greatly affected by the substrate bias, indicating that most of the flux is neutral at the sputtering power of $10 \mathrm{~W}$.

At the plasma power of $200 \mathrm{~W}$, however, the thickness of the Ag films was affected by the substrate bias, as shown in Fig. 8. The Ag films deposited under the substrate biases of $-300,0$, and $+300 \mathrm{~V}$ had thicknesses of $68.9 \pm 2.3$, $77.6 \pm 1.4$ and $83.5 \pm 3.6 \mathrm{~nm}$, respectively. The maximum and minimum film thicknesses were observed at substrate
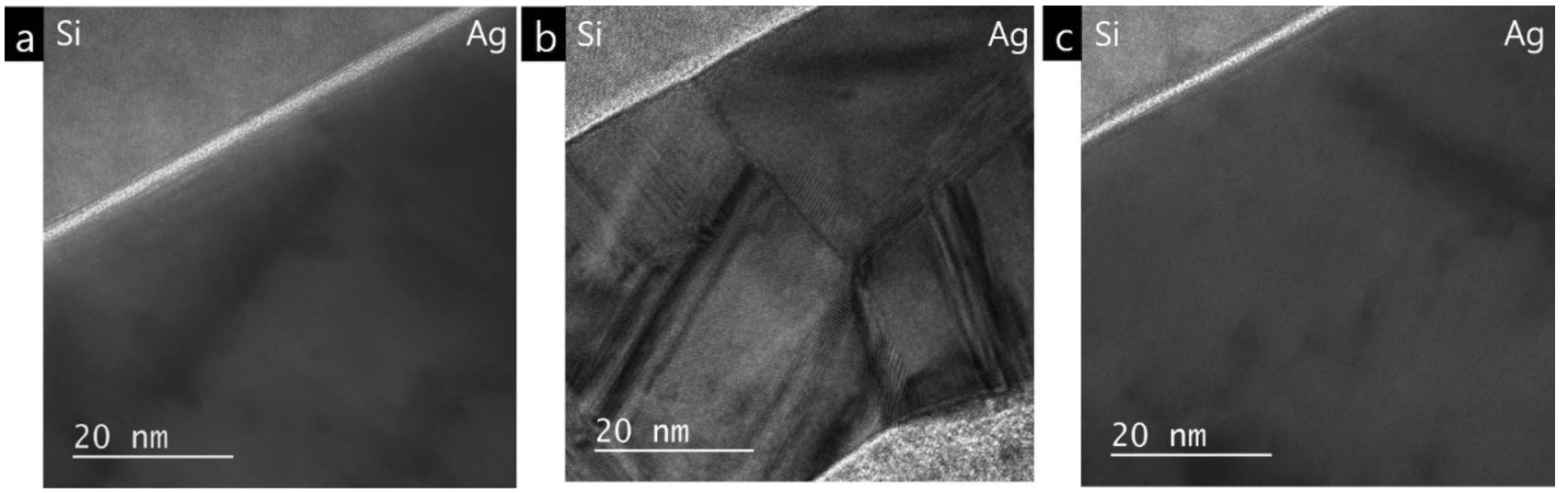

Fig. 5 Low-magnification TEM images of Ag films deposited on Si substrates at sputtering powers of a $10 \mathrm{~W}$ b $50 \mathrm{~W}$ and $\mathbf{c} 200 \mathrm{~W}$ 
Fig. 6 HRTEM and FFT images of Ag films deposited on $\mathrm{Si}$ substrates at sputtering powers of a $10 \mathrm{~W}$ b $50 \mathrm{~W}$ and c $200 \mathrm{~W}$. The triangle mark is a peak of 4H-Ag HCP and the circle mark is a peak of 3C-Ag FCC in FFT images
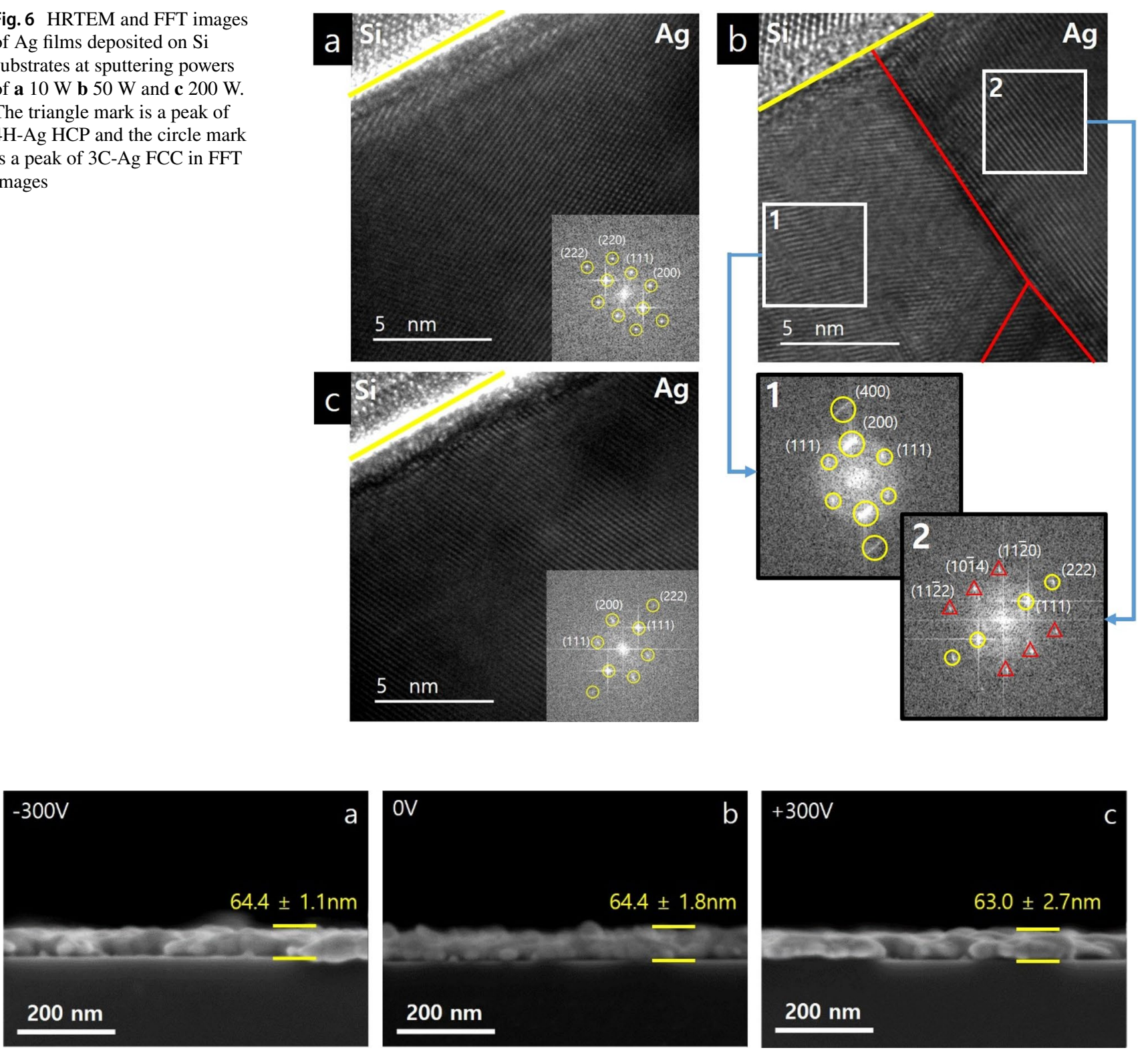

Fig. 7 Cross-sectional FESEM images of Ag films deposited on Si substrates at the electric biases of $\mathbf{a}-300 \mathrm{~V} \mathbf{b} 0 \mathrm{~V}$ and c $+300 \mathrm{~V}$ with a sputtering power of $10 \mathrm{~W}$
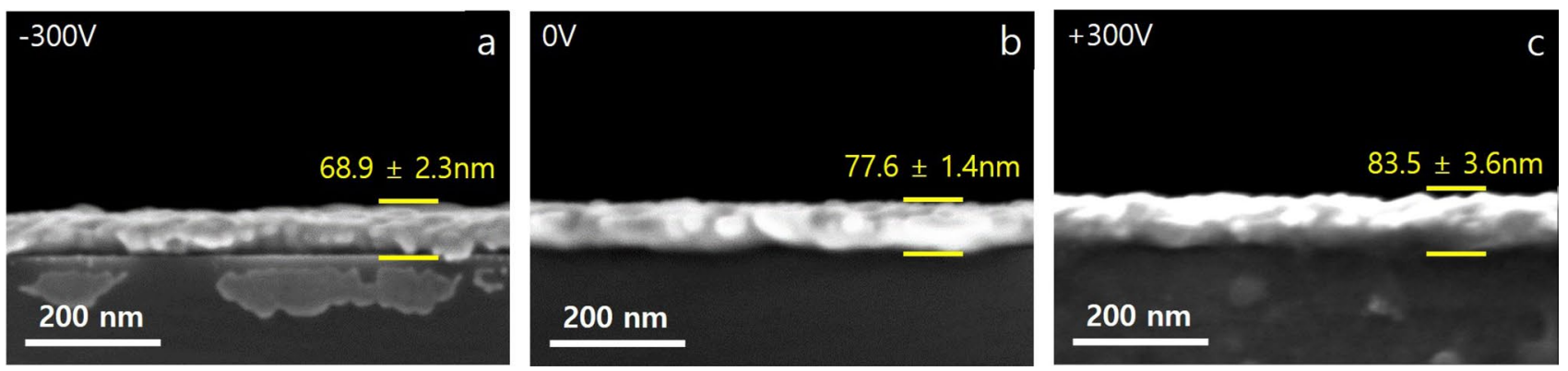

Fig. 8 Cross-sectional FESEM images of Ag films deposited on Si substrates at the electric biases of $\mathbf{a}-300 \mathrm{~V} \mathbf{b} 0 \mathrm{~V}$ and $\mathbf{c}+300 \mathrm{~V}$ with a sputtering power of $200 \mathrm{~W}$ 
biases of +300 and $-300 \mathrm{~V}$, respectively. These results indicate that some of the sputtered Ag flux is negatively charged, and the percentage of the $\mathrm{Ag}$ sputtered flux that is positively charged is negligibly small.

The film thickness of $68.9 \pm 2.3 \mathrm{~nm}$ deposited at $-300 \mathrm{~V}$ is $11.2 \%$ less than that of $77.6 \pm 1.4 \mathrm{~nm}$ deposited at $0 \mathrm{~V}$, indicating that $\sim 11 \%$ of the sputtered flux is repelled by the bias of $-300 \mathrm{~V}$. The film thickness of $83.5 \pm 3.6 \mathrm{~nm}$ deposited at $+300 \mathrm{~V}$ is $7.6 \%$ larger than that of $77.6 \pm 1.4 \mathrm{~nm}$ deposited at $0 \mathrm{~V}$, indicating that $\sim 8 \%$ of the sputtered flux is attracted by the bias of $+300 \mathrm{~V}$. According to these results, roughly $10 \%$ of the flux is negatively charged.

\section{Conclusions}

The growth rate and quality of Ag films were affected by the sputtering power during deposition by DC magnetron sputtering. When the sputtering power is $10 \mathrm{~W}$, most of the flux appears to be in the form of individual atoms, producing the highest quality film but with the lowest growth rate. At a sputtering power of $200 \mathrm{~W}$, a relatively high film quality was obtained at the highest film growth rate. The degradation of film quality with increasing sputtering power is attributed to the generation of neutral clusters during sputtering. The improvement of film quality with a further increase in sputtering power is attributed to the generation of charged clusters during sputtering. The most important finding of this paper is that the charge plays an important role in the deposition of $\mathrm{Ag}$ films and that if the fraction of charged clusters is increased, the high quality film can be grown at a high deposition rate.

Acknowledgements This research was supported by Global Frontier Program through the Global Frontier Hybrid Interface Materials (GFHIM) of the National Research Foundation of Korea (NRF) funded by the Ministry of Science, ICT and Future Planning (MSIT) (Number NRF-2013M3A6B1078874) and the National Research Foundation of Korea (NRF) grant funded by the Korea government (MSIT) (number 2020R1A5A6017701) and BK21PLUS SNU Materials Division for Educating Creative Global Leaders (21A20131912052).

Open Access This article is licensed under a Creative Commons Attribution 4.0 International License, which permits use, sharing, adaptation, distribution and reproduction in any medium or format, as long as you give appropriate credit to the original author(s) and the source, provide a link to the Creative Commons licence, and indicate if changes were made. The images or other third party material in this article are included in the article's Creative Commons licence, unless indicated otherwise in a credit line to the material. If material is not included in the article's Creative Commons licence and your intended use is not permitted by statutory regulation or exceeds the permitted use, you will need to obtain permission directly from the copyright holder. To view a copy of this licence, visit http://creativecommons .org/licenses/by/4.0/.

\section{References}

1. Markov, I.V.: Crystal Growth for Beginners. World Scientific (2003)

2. Feng, X., Gao, R., Wang, R., Zhang, G.: Non-classical crystal growth on a hydrophobic substrate: learning from bivalve nacre. CrystEngCommun 22(18), 3100-3105 (2020). https://doi. org/10.1039/D0CE00076K

3. Lizandara-Pueyo, C., Dilger, S., Wagner, M.R., Gerigk, M., Hoffmann, A., Polarz, S.: Li-doped ZnO nanorods with singlecrystal quality-non-classical crystallization and self-assembly into mesoporous materials. CrystEngCommun 16(8), 1525-1531 (2014). https://doi.org/10.1039/C3CE41670D

4. Rodríguez-Navarro, C., Ruiz-Agudo, E., Harris, J., Wolf, S.E.: Nonclassical crystallization in vivo et in vitro (II): nanogranular features in biomimetic minerals disclose a general colloid-mediated crystal growth mechanism. J. Struct. Biol. 196(2), 260-287 (2016). https://doi.org/10.1016/j.jsb.2016.09.005

5. Sadri, B., Pernitsky, D., Sadrzadeh, M.: Aggregation and deposition of colloidal particles: effect of surface properties of collector beads. Colloids Surf., A 530, 46-52 (2017). https://doi. org/10.1016/j.colsurfa.2017.07.041

6. Gebauer, D., Völkel, A., Cölfen, H.: Stable prenucleation calcium carbonate clusters. Science 322(5909), 1819 (2008). https://doi. org/10.1126/science. 1164271

7. Hwang, N.M.: Non-Classical Crystallization of Thin Films and Nanostructures in CVD and PVD Processes. Springer Series in Surface Sciences. Springer, Netherlands (2016)

8. Jung, J.-S., Lee, S.-H., Kim, D.-S., Kim, K.-S., Park, S.-W., Hwang, N.-M.: Non-classical crystallization of silicon thin films during hot wire chemical vapor deposition. J. Cryst. Growth $\mathbf{4 5 8}$, 8-15 (2017). https://doi.org/10.1016/j.jcrysgro.2016.10.023

9. Niederberger, M., Cölfen, H.: Oriented attachment and mesocrystals: non-classical crystallization mechanisms based on nanoparticle assembly. Phys. Chem. Chem. Phys. 8(28), 3271-3287 (2006). https://doi.org/10.1039/B604589H

10. De Yoreo, J.J., Gilbert, P.U.P.A., Sommerdijk, N.A.J.M., Penn, R.L., Whitelam, S., Joester, D., Zhang, H., Rimer, J.D., Navrotsky, A., Banfield, J.F., Wallace, A.F., Michel, F.M., Meldrum, F.C., Cölfen, H., Dove, P.M.: Crystallization by particle attachment in synthetic, biogenic, and geologic environments. Science 349(6247), 6760 (2015). https://doi.org/10.1126/science.aaa6760

11. Cölfen, H.: Mesocrystals and Nonclassical Crystallization. Wiley, London (2008)

12. Jehannin, M., Rao, A., Cölfen, H.: New horizons of nonclassical crystallization. J. Am. Chem. Soc. 141(26), 10120-10136 (2019). https://doi.org/10.1021/jacs.9b01883

13. Abd El-Fattah, H.A., El-Mahallawi, I., Shazly, M.H., Khalifa, W.A.: Microstructure evolution of NiTi magnetron sputtered thin film on different substrates. Key Eng. Mater. 835, 68-74 (2020). https://doi.org/10.4028/www.scientific.net/KEM.835.68

14. Amos, F.F., Dai, L., Kumar, R., Khan, S.R., Gower, L.B.: Mechanism of formation of concentrically laminated spherules: implication to Randall's plaque and stone formation. Urol. Res. 37(1), 11-17 (2009). https://doi.org/10.1007/s00240-008-0169-x

15. Song, R., Krasia-Christoforou, T., Debus, C., Cölfen, H.: Structure and magnetic property control of copper hydroxide acetate by non-classical crystallization. Small 13(9), 1602702 (2017). https ://doi.org/10.1002/smll.201602702

16. Kim, D., Kim, D.Y., Kwon, J.H., Kim, K.-S., Hwang, N.-M.: Generation of charged SiC nanoparticles during HWCVD process. Electron. Mater. Lett. 16(5), 498-505 (2020). https://doi. org/10.1007/s13391-020-00230-3

17. Youn, W.-K., Lee, S.-S., Lee, J.-Y., Kim, C.-S., Hwang, N.-M., Iijima, S.: Comparison of the deposition behavior of charged 
silicon nanoparticles between floating and grounded substrates. J. Phys. Chem. C 118(22), 11946-11953 (2014). https://doi. org/10.1021/jp5001144

18. Park, S.-W., Jang, G.-S., Kim, K.-S., Hwang, N.-M.: Comparison of plasma effect on dewetting kinetics of Sn films between grounded and floating substrates. Electron. Mater. Lett. 16(1), 72-80 (2020). https://doi.org/10.1007/s13391-019-00190-3

19. Park, S.-W., Jung, J.-S., Kim, K.-S., Kim, K.-H., Hwang, N.-M.: Effect of bias applied to the substrate on the low temperature growth of silicon epitaxial films during RF-PECVD. Cryst. Growth Des. 18(10), 5816-5823 (2018). https://doi.org/10.1021/ acs.cgd.8b00384

20. Yamaguchi, N., Sasajima, Y., Terashima, K., Yoshida, T.: Molecular dynamics study of cluster deposition in thermal plasma flash evaporation. Thin Solid Films 345(1), 34-37 (1999). https://doi. org/10.1016/S0040-6090(99)00074-7

21. Terashima, K., Norio, Y., Tomoyuki, H., Takamura, Y., Yoshida, T.: High rate deposition of thick epitaxial films by thermal plasma flash evaporation. Pure Appl. Chem. 70(6), 1193-1197 (1998). https://doi.org/10.1351/pac199870061193

22. Kwon, J.-H., Kim, D.-Y., Hwang, N.-M.: Generation of charged Ti nanoparticles and their deposition behavior with a substrate bias during RF magnetron sputtering. Coatings 10(5), 58 (2020). https ://doi.org/10.3390/coatings 10050443

23. Jang, G.-S., Kim, D.-Y., Hwang, N.-M.: The effect of charged ag nanoparticles on thin film growth during DC magnetron sputtering. Coatings 10(8), 51 (2020). https://doi.org/10.3390/coatings10 080736

24. Bauer, W., Betz, G., Bangert, H., Bergauer, A., Eisenmenger-Sittner, C.: Intrinsic resputtering during film deposition investigated by Monte Carlo simulation. J. Vac. Sci. Technol., A 12(6), 3157-3164 (1994). https://doi.org/10.1116/1.579231
25. Chen, J., Suwardy, J., Subramani, T., Jevasuwan, W., Takei, T., Toko, K., Suemasu, T., Fukata, N.: Control of grain size and crystallinity of poly-Si films on quartz by Al-induced crystallization. CrystEngComm 19(17), 2305-2311 (2017). https://doi. org/10.1039/C6CE02328B

26. Muniz, F.T., Miranda, M.A., Morilla, D.S.C., Sasaki, J.M.: The Scherrer equation and the dynamical theory of X-ray diffraction. Acta Crystallographica. Section A. Found. Adv. 72(3), 385-390 (2016). https://doi.org/10.1107/s205327331600365x

27. Rieth, L.W., Holloway, P.H.: Influence of negative ion resputtering on $\mathrm{ZnO}$ : Al thin films. J. Vac. Sci. Technol. A 22(1), 20-29 (2003). https://doi.org/10.1116/1.1626641

28. Chakraborty, I., Shirodkar, S.N., Gohil, S., Waghmare, U.V., Ayyub, P.: The nature of the structural phase transition from the hexagonal $(4 \mathrm{H})$ phase to the cubic $(3 \mathrm{C})$ phase of silver. J. Phys. Condens. Matter 26(11), 115405 (2014). https://doi. org/10.1088/0953-8984/26/11/115405

29. Novgorodova, M.I., Gorshkov, A.I., Mokhov, A.V.: Native silver and its new structural modifications. Int. Geol. Rev. 23(4), 485-494 (1981). https://doi.org/10.1080/00206818109455083

30. Jeon, I.-D., Barnes, M.C., Kim, D.-Y., Hwang, N.M.: Origin of positive charging of nanometer-sized clusters generated during thermal evaporation of copper. J. Cryst. Growth 247(3), 623-630 (2003). https://doi.org/10.1016/S0022-0248(02)02058-4

Publisher's Note Springer Nature remains neutral with regard to jurisdictional claims in published maps and institutional affiliations. 